\title{
An Overview and Critique of NCAA Policy Regarding the Use of Sport Psychology Consultants at the Division I Level
}

\author{
James H. Bemiller and Craig A. Wrisberg \\ University of Tennessee, Knoxville
}

\begin{abstract}
Over the past 20 years the National Collegiate Athletic Association Division-I (NCAA) has restricted the activities of sport psychology consultants (SPCs) working with student-athletes, particularly at the Division I (D-I) level. In some cases, the restrictions have been based on the assumption that what SPCs do is actually "coaching." Thus, if SPCs are permitted to interact with student-athletes during practices and competitions they must be considered as "countable" coaches. In this paper, we briefly discuss the history of NCAA rules governing the activities of SPCs, provide excerpts from the sport psychology literature and the NCAA D-I Manual that illustrate how the specialized work of SPCs is different from that of coaches, suggest reasons why allowing student-athletes and coaches access to SPCs during practices and competitions would be beneficial to both groups, and propose ways NCAA legislation might be amended to allow SPCs to work with student-athletes in a manner similar to the ways other athletic department support personnel (e.g., athletic trainers and strength and conditioning coaches) are permitted to do.
\end{abstract}

While the conceptual roots of applied sport psychology date to early Greek and Asian cultures (Mahoney, 1989), the emergence of sport psychology consultants (SPCs) and psychological skills training (PST) as a significant component of athletes' competition preparation is a relatively recent phenomenon. The contemporary literature suggests that a growing number of today's sport competitors are complementing their physical training and conditioning with PST and turning to SPCs for various forms of assistance (Kornspan \& Duve, 2006; Voight \& Callaghan, 2001; Wrisberg, Simpson, Loberg, Withycombe, \& Reed, 2009). According to one source, such assistance includes "ways to manage competitive stress, control concentration, improve confidence, and increase communication skills and team harmony" (Williams \& Straub, 2010, p. 1).

One population for whom an exposure to PST could be beneficial are collegiate student-athletes; particularly those competing at the National Collegiate Athletic Association Division I (NCAA D-I) level where an inordinate emphasis on winning has the potential to negatively affect both performance and life quality

The authors are with the Department of Kinesiology, Recreation, and Sport Studies at the University of Tennessee, Knoxville, TN. 
(Wrisberg \& Johnson, 2002). In 1988 the NCAA sponsored a study that revealed that student-athletes had higher levels of stress and longer recovery periods than a control sample of nonathletes involved in other extracurricular activities (i.e., band) (American Institutes for Research, 1988). These results prompted the creation of an NCAA rule (Bylaw 17.1.6.1) restricting the amount of time in season that studentathletes could be involved with their respective sports to 20 hours a week (NCAA, 2010). However, no formal action was taken to encourage the use of SPCs to assist student-athletes in managing the mental and emotional challenges of participation.

Notwithstanding, a few athletic departments began providing sport psychology services for the benefit of the student-athlete on a limited basis (Wrisberg \& Whitney, 1999). One survey of 96 NCAA D-I athletic departments (Voight \& Callaghan, 2001) revealed that 53\% provided some form of sport psychology consulting; however the terms of employment and nature of the services varied widely across programs. The highest percentage of departments employed part-time consultants to work with either individual sport programs $(37 \%)$ or the entire athletic department $(20 \%)$. A smaller percentage employed full-time consultants (14\%) while the remainder used the services of exercise science faculty or graduate student volunteers, members of university counseling center staff, athletic academic counseling personnel, or individuals hired by the sports medicine office. Consultants' services ranged from PST that focused on goal setting, attention control, visualization, and relaxation to clinical counseling for the purposes of crisis intervention and injury recovery, to psychological testing (e.g., brain typing).

Subsequent studies revealed both a heightened perception among athletic directors (ADs) of the need for consultants yet some lingering uncertainty as to the value of SPCs' services. In one study $82 \%$ of the participants, all of whom were NCAA D-I ADs, responded "yes" or "on a part-time basis" to the question of whether there was a need to hire a SPC at their institution (Kornspan \& Duve, 2006). However, the results of another study (Wilson, Gilbert, Gilbert, \& Sailor, 2009 ) revealed that ADs placed a relatively lower value on services provided by SPCs than on those provided by more established support staff (i.e., athletic trainers and strength and conditioning coaches). As one AD commented, "I think most (ADs) see sports psychology as beneficial, but an enhancement, rather than a basic requirement" (Wilson et al., 2009, p. 414). Taken together, the findings of previous research suggest that since the early 1990s there has been an increase in the number of sport psychology services provided by NCAA D-I athletic departments but that the type of services has varied and the perceptions of the role and value of SPCs have remained equivocal.

Recent studies with NCAA D-I student-athletes and coaches suggest that both groups are receptive to mental training services and supportive of a role for a SPC in the athletic department. A majority (i.e., > 50\%) of the NCAA D-I student-athletes in one study $(n=2440)$ rated as "high" their willingness to seek mental training assistance for enhancing performance as well as their support of a role for a SPC that involved either providing occasional services or holding a full-time athletic department staff position (Wrisberg et al., 2009). In another study of NCAA D-I coaches $(n=815)$ over $65 \%$ rated as "favorable" their willingness to seek mental training for their student-athletes for performance enhancement purposes (e.g., dealing with pressure, building confidence, improving focus, managing anxiety, 
managing emotions). Moreover, the frequency of "favorable" ratings was significantly higher for coaches that had more frequent contact with SPCs (i.e., > 5 meetings vs. 1-5 meetings or no contact) and perceived the effectiveness of services to be "high" as opposed to "moderate" or "low" (Wrisberg, Loberg, Simpson, Withycombe, \& Reed, 2010).

In spite of what appears to be a growing openness to sport psychology services by ADs, coaches, and student-athletes at the D-I level, NCAA regulations governing the activities of SPCs has been relatively restrictive (NCAA, 2010). In the remainder of this paper we provide an overview of this legislative history along with examples of how it has impacted the work of SPCs working to benefit student athletes. Based on his own experiences the second author begins by depicting the reaction he and other SPCs had to initial NCAA interpretations that limited their work and describes a number of futile attempts made by representatives of the Association for the Advancement of Applied Sport Psychology (AAASP) and Division 47 of the American Psychological Association (APA) to open communication with the NCAA and request a change in policy. We conclude the paper by (a) discussing excerpts from the sport psychology literature and the NCAA Division I Manual that illustrate how the work of SPCs is not the same as that of coaches; (b) suggesting reasons why allowing NCAA D-I student-athletes and coaches access to SPCs during practices and competitions would be beneficial to the student-athlete, and (c) proposing ways NCAA legislation might be amended to allow SPCs to work with student-athletes in a manner similar to other athletic department support personnel (e.g., athletic trainers and strength and conditioning coaches).

\section{Overview of the History of NCAA Legislation Concerning Its Impact on the Work of SPCs}

In addition to my work as a professor of sport psychology, I have provided mental training assistance for student-athletes at the University of Tennessee since 1981 (Wrisberg \& Whitney, 1999). My involvement began in the spring of that year when one of the students in my graduate sport psychology class, who also happened to be the women's collegiate volleyball coach, approached me to discuss the possibility of meeting with his team. What began as occasional facilitation of postmatch discussions of players' impressions of the things that stood out for them in the competition eventually evolved into periodic team mental training sessions. Over the next 10 years, I was approached by coaches from other sports and provided assistance for individual student-athletes and teams as requested, initially on a volunteer basis and later for payment by the athletic department. In each of these situations I spent the majority of my time attending practices and getting to know the student-athletes. Once they became comfortable with my presence, several would usually approach me to request individual assistance with their mental game (i.e., dealing with pressure, managing emotions, focusing, developing effective mental strategies and routines, etc.). In 1991, the AD invited me to submit a formal proposal for the provision of mental training services that would enable any coach or student-athlete to obtain assistance. He subsequently approved the proposal and provided the resources necessary for me to provide PST services on an "as 
needed" basis. This arrangement continued smoothly until June 1995 when the athletic department's compliance officer informed me of a new NCAA Legislative Services Staff Interpretation that had the potential to restrict my interactions with student-athletes (NCAA LSDBi, 2010). The interpretation read as follows:

Sports Psychologist Present at Practice Sessions: The legislative services staff determined that in Division I (italics added), an institution's sports psychologist may not attend institutional practice sessions for the purpose of evaluating a student-athlete(s) without being included in the institution's coaching limitations in the applicable sport. [References: NCAA Manual, Bylaws 11.7.1.1.1 (countable coach) and 11.7.1.1.1.1 (non-coaching activities)]

Upon reading this interpretation I immediately obtained a copy of the NCAA Manual to find out more about the two bylaws referenced as a basis for the interpretation (NCAA LSDBi, 2010). They read, respectively, as follows:

\subsection{Countable Coach}

An athletics department staff member must count against the coaching limits as soon as the individual participates (in any manner) in the coaching of the intercollegiate team in practice, games or organized activities directly related to that sport, including any organized staff activity directly related to the sport. ${ }^{1}$

\subsection{Noncoaching Activities}

Institutional staff members involved in noncoaching activities (e.g., administrative assistants, academic counselors) do not count in the institution's coaching limitations, provided such individuals are not identified as coaches, do not engage in any on- or off- field coaching activities (e.g., attending meetings involving coaching activities, analyzing videotape or film involving the institution's or an opponent's team), and are not involved in any off-campus recruitment of prospective student-athletes or scouting of opponents. A noncoaching staff member with sport-specific responsibilities may not participate with or observe student-athletes in the staff member's sport who are engaged in nonorganized voluntary athletically related activities (e.g., pick-up games) (NCAA LSDBi, 2010).

With no apparent supporting evidence, the NCAA Legislative Services Staff had determined that at least some individuals with the title "sports psychologist" were violating the NCAA rule governing the number of allowable coaches by performing coaching duties rather than the duties of other noncoaching staff members. (Note: Nowhere in this legislation or the supporting bylaws was other support staff, such as athletic trainers or strength coaches, mentioned. We will return to this point later in the paper).

The issuance of this legislation produced immediate changes in the allowable activities of SPCs working with NCAA D-I student-athletes and generated considerable anxiety in the professional sport psychology community. Qualified SPCs that had been working with college athletes for a number of years wondered why they were being singled out for such restrictions and, more importantly, why the 
NCAA was compromising SPCs' effectiveness by denying them interaction with student-athletes in the very situations where their services could be of the greatest benefit (i.e., intense practice sessions and competitions). Knowing that I had provided mental training at the NCAA D-I level for many years and had served as a member of the AAASP Certified Consultants Committee, other SPCs working with collegiate student-athletes began contacting me to state their concerns and solicit my opinion as to how they should proceed. At the same time AAASP requested that I serve as chair of an ad hoc NCAA Concerns Committee charged with the task of exploring strategies for opening better lines of communication with the NCAA. The committee included one member of APA Division 47 who was responsible for keeping their members apprised of the committee's ongoing activities. The consensus was that a face-to-face meeting with the NCAA Chief Legislative Officer would be the best "first step" so a visit to NCAA headquarters was scheduled in September 1996. During that visit the AAASP President and I discussed the aforementioned legislation with the Chief Legislative Officer, explained AAASP's commitment to improving the welfare of student-athletes, which had been a theme emphasized by the NCAA since the 1988 study (American Institutes for Research, 1988), and described AAASP's efforts in developing a process for certifying qualified SPCs. At the suggestion of the officer, the Concerns Committee prepared a written proposal requesting a rule change that would allow SPCs to interact with student-athletes at practices and competitions. The proposal was submitted to the Division I Steering Committee of the NCAA Council for discussion at its meeting in April 1997. In July, the Chief Legislative Officer informed me of the committee's decision in the following memo:

The Division I Steering Committee of the NCAA Council reviewed your group's request during its April 14-15 meeting. They declined to sponsor legislation to permit Division I institutions to employ sports psychologists (either on a temporary or permanent basis) to assist student-athletes in the development of psychological skills prior to any competition and prior to or during any practice or other organized activities without including such individuals in the coaching limits. The council was provided all of the information and suggestions submitted by your group. I was not at the meeting, but I was informed that there just did not seem to be a lot of support for the idea. I think the primary concerns related to competitive equity (notwithstanding the proposed safeguards) and, to some degree, proliferation of personnel. Sorry I cannot give you better news (S. A. Mallonee, personal communication, July 1, 1997).

I subsequently contacted the Legislative Officer and learned that he was planning to attend a collegiate football game in Knoxville during the 1997 season. I asked if he and I could meet to discuss some possible "next steps." He agreed and later, after that meeting, he sent me the following e-mail message:

Regarding the sport psychologist proposal, I really think that because of the membership's apparent skepticism related to their use, the best avenue is to continue to pursue a legislative exception to the coaching limitations, particularly if there is interest in allowing such individuals to attend team practices or meetings. There are two ways that legislative ideas can be introduced in the new 
structure: 1) a conference (e.g., Big 10, Big 12, SEC, etc.) can submit the idea directly to the Management Council. In most cases, the Management Council will then forward it down to the appropriate cabinet, which in this instance would be the Championships/Competition Cabinet, or 2) an institution or even a group can submit an idea to the appropriate cabinet (i.e., the Championships/ Competition Cabinet) and ask them to consider sponsoring it as a legislative proposal. Such an idea can be submitted to the staff liaison for consideration by the cabinet at its next meeting. The liaisons to that cabinet (names)... are here at the National Office. I would advise going with the second alternative (S. A. Mallonee, personal communication, October 21, 1997). ${ }^{2}$

In response to this advice, I contacted the NCAA Concerns Committee member representing the interests of APA Division 47 and requested his assistance in helping me revise our original proposal. ${ }^{3}$ After we completed the revision we forwarded it to one of the NCAA staff liaisons. In a few weeks she emailed me confirming that she had received the proposal and added the following comment:

In our governance structure, proposed legislative amendments are submitted only by institutions or conferences, not by outside organizations. What I can do is ask the Division I Championships/Competition Cabinet if it is interested in discussing the proposal and possibly moving it through the structure. If it isn't, then it would have to be submitted by an institution or conference (T. Bork, personal communication, January 15, 1998).

I requested that she ask the cabinet to discuss the proposal and shortly after their meeting in February 1998 received the following note:

The Administrative Committee of the Championships/Competition Cabinet did review the proposal and did not wish to move it through the structure. They noted that this proposal had previously been reviewed but not supported by the Council (in the old NCAA structure) (T. Bork, personal communication, February 24, 1998).

Upon receiving this message I again contacted the Chief Legislative Officer for his reaction and obtained the following response:

I am not sure what to tell you at this point. I do think the Administrative Committee of the Championships/Competition Cabinet reviewed your material and from what I understand there just does not seem to be support at this time to pursue a proposal to permit the purpose of evaluating or assisting student-athletes. I do not know what other avenue to suggest except to perhaps let this one go for a while (S. A. Mallonee, personal communication, February 27, 1998).

After sharing the previous response with members of our NCAA Concerns Committee, we decided to follow the officer's suggestion and perhaps submit the proposal again at a later time. In April 1998 I conveyed the committee's decision to the AAASP Executive Board.

Clearly, the times had changed for SPCs working with student-athletes at the D-I level, although some athletic departments continued to seek clarification from 
the NCAA regarding the allowable activities of SPCs. For example, in February 2001 I was copied on a letter to the AAASP President from a SPC at one prominent D-I university expressing concern over a NCAA Staff interpretation the Compliance Officer at his institution had obtained. The following is an excerpt from that letter:

I am a sport psychology performance consultant from (NCAA D-I university) and member of AAASP for several years. The reason for my letter is to inform you about a recent NCAA rules interpretation regarding sport psychology. My objective in writing this letter is to see if AAASP can look into this matter further. The Director of Compliance at (NCAA D-I university) made a formal inquiry to the (conference) office first, then to the NCAA, to determine the exact rules governing the use of sport psychologists by collegiate athletic departments. The officer was asked to do so by our Athletic Director who was concerned about the rules regarding the use of a sport psychologist (me). I have been working with programs at (NCAA D-I university) for over 3 years. The interpretation was received by the compliance officer on January 27, 2001. According to the NCAA Director of Legislative Services, it is permissible for a sport psychologist to work individually with student-athletes, but it is not permissible for a sport psychologist to attend practice for the purpose of evaluation. Evaluation at practice was defined as:

NOT limited to just athletic ability. Watching practice and giving feedback on student-athlete interaction and how a student-athlete implements psychological strategies are all designed to assist the student-athlete in improving his or her athletics ability and are activities that are arguably the responsibility of a coach. Outside consultants generally are not supposed to be at practice, unless they count in the coaching limitations.

Throughout my training in sport psychology, as well as the numerous sessions I have attended at professional conferences, I have always been told the importance of attending practice sessions when you are a sport psychology consultant. Not only being there to support/encourage athletes, but being there to observe the workings of the organization, to learn more about the game, to evaluate progress made by the athlete(s), and converse with the coaching staff, are all integral parts of the consultation process. I know that I would not be as effective a consultant with my (college) teams without attending practice sessions (M. Voight, personal communication, February 12, 2001).

As noted in the previous letter, the Legislative Officer's interpretation of "evaluation" now included "giving feedback on student-athlete interaction and how a student-athlete implements a psychological strategy" and constituted activities "designed to assist the student-athlete in improving his or her athletic ability," which was "arguably the responsibility of a coach."

The most consistent, though puzzling, aspect of NCAA legislation restricting the activities of SPCs working with D-I student-athletes is the way the work of SPCs has been characterized as "coaching." This begs the question of why the NCAA assumes SPCs might be acting as coaches when it appears to hold no such assumption for other support staff providing specialized assistance (e.g., athletic trainers, 
strength coaches). ${ }^{4}$ Within the sport psychology community the rumor has persisted that the initial impetus for NCAA sanctions was a particular event involving a successful NCAA D-I basketball coach and one of his student-athletes. Presumably, the coach had been using a former professional player to assist the athlete with his offensive skills. When an NCAA official, who happened to be visiting the campus, observed the "instruction" taking place, he asked the coach what the "instructor" was doing. The coach answered, "He's our sport psychologist." 5

The most recent NCAA Staff Interpretations directly relating to SPCs were published in 2003 and read as follows:

Sports Psychologists Attending Practice Sessions, January 8, 2003.

It is permissible for a sports psychologist to attend practice sessions without including such an individual in the institution's coaching limitations, provided the individual does not participate in any coaching activities. The sports psychologist may evaluate a student-athlete during a practice session only for the purposes of assisting the student-athlete in off-court or off-field noncoaching activities (e.g., mental imagery) directly related to the sport (NCAA LSDBi, 2010).

Sports Psychology/Use of Outside Consultants, July 2, 2003.

It is permissible for an institution's athletics department to employ a sports psychologist without including such an individual in the institution's coaching limitations in a particular sport, provided the individual does not engage in any on- or off-field coaching activities (e.g., use equipment, review game films, set-up offensive or defensive alignments when meeting with the studentathletes, meetings involving coaching activities). A sports psychologist may engage in "mental imaging" with a student-athlete without being considered a countable coach, provided no coaching activities occur; however, if a studentathlete is required to meet with the sports psychologist, such a meeting is considered a countable athletically related activity (NCAA LSDBi, 2010).

Notwithstanding these attempts to clarify the use of sport psychologists, NCAA interpretations continue to restrict meaningful interaction between student-athletes and SPCs during practices. ${ }^{6}$

Except for the initial efforts made by AAASP to clarify what SPCs do, it appears that the field of sport psychology has yet to provide the NCAA with satisfactory responses to the following two questions:

- How is what NCAA D-I SPCs do different from what coaches do?

- Why should SPCs be allowed to interact with student-athletes during practices and competitions?

Therefore, in the remainder of this paper we offer possible answers to these questions based on NCAA legislation as well as excerpts from the extant sport psychology literature. In our response to the first question we italicize portions to emphasize differences between the work of SPCs and coaches. In our second answer we include citations from the sport psychology literature, the original proposal 
submitted by the AAASP NCAA Concerns Committee, and a memo written by a NCAA D-I SPC to the compliance officer at her athletic department. ${ }^{7}$ We conclude the paper by suggesting possible changes to NCAA legislation that would allow SPCs to interact with NCAA D-I student-athletes at practices and competitions for the optimal benefit of the student athletes.

\section{How Does What NCAA D-I SPCs Do Differ From What Coaches Do?}

Conceptualizations of the field of applied sport psychology and the activities of SPCs can be found in numerous places in the sport psychology literature. The following excerpts represent just a few examples. The first contains a general characterization of the field.

Applied sport psychology is concerned with the psychological factors that influence participation and performance in sport and exercise, the psychological effects derived from participation, and theories and interventions that can be used to enhance performance, participation, and personal growth (Williams \& Straub, 2010, p. 13).

A key modifier in the previous statement is the word "psychological." The authors emphasize the point that qualified SPCs are able to teach sport participants psychological skills for managing competitive stress, controlling concentration, improving confidence, and increasing communication and team harmony.

In the following two citations the potential impact of SPCs' services are broadened to include the enhancement of participants' life quality.

Applied sport and exercise psychology professionals are interested in how participation in sport, exercise, and physical activity may enhance personal development and well-being throughout the life span (Association for Applied Sport Psychology, 2011).

Sport psychology consultants who are capable of teaching psychological skills effectively can substantially contribute to athletes' mental preparation in their quest for optimal performance, development as sport participants, and increased sport and life satisfaction. (Tod \& Andersen, 2004, p. 306).

As noted previously the NCAA is also on record as being committed to collegiate student-athlete well-being. Article 2 of the NCAA Constitution (Principle 2.2) contains the following statement, "Intercollegiate athletics programs shall be conducted in a manner designed to protect and enhance the physical and educational well-being of student-athletes." (NCAA, 2010).

The website of the Association for Applied Sport Psychology (AASP) ${ }^{8}$ delineates the various services SPCs can offer depending on their training (Association for Applied Sport Psychology, 2011). These include the teaching of "specific mental, behavioral, psychosocial, and emotional control skills for sport, exercise, 
and physical activity contexts" such as "relaxation, concentration, or the use of imagery." It should be noted that the psychological skills mentioned here are appropriate for a variety of sport and exercise settings in addition to competitive collegiate athletics. Moreover, the potential benefits of PST for any individuals performing activities requiring the maintenance of focus and composure under pressure (e.g., dancers, musicians, brain surgeons, astronauts, military personnel, etc.) would arguably be the same as for collegiate athletes.

The next excerpt illustrates how the field of sport psychology has attempted to emphasize differences in what SPCs and coaches do in their respective attempts to assist athletes in achieving their goals.

As sport psychology has become more established as a profession, its language has become more consistent, reflecting the common goals of mental-skills training... Most athletes find that talking to a sport psychologist is as natural as talking to a coach. The major difference is that the work with sport psychologists focuses on the mental aspects of sport rather than the technical and physical aspects (McCann, 2004, pp. 279-280).

Taken together, the preceding examples from the sport psychology literature clearly indicate that the primary role of SPCs is to provide psychological assistance for sport and exercise performers in meeting the mental challenges of participation. In contrast, the following examples of coaches' activities cited in various NCAA bylaws, staff interpretations, and educational columns suggest that their primary responsibility is to assist athletes in technical and tactical ways. Such duties include analyzing video involving the institution's or an opponent's team, scouting of opponents (NCAA Bylaw 11.7.1.1.1.1); using equipment, reviewing game films, setting up offensive or defensive alignments (Staff Interpretation-Sports Psychologist/Use of Outside Consultants); pitching batting practice (Educational Column-2004 Hot Topic \#2-Noncoaching Staff Participation in Practice); and formulating game plans (NCAA Bylaw 11.7.1.1.1.4-Use of Outside Consultants) (NCAA LSDBi, 2010). ${ }^{9}$

While none of the previous examples specifically mention psychological assistance, it is reasonable to assume that at least some of the work coaches do with athletes has a psychological purpose. However, the important issue in the present paper is whether the type of psychological assistance coaches provide for athletes is substantially similar to that provided by SPCs. Perusal of both the popular coaching literature (e.g., Alvarez, 2006) and academic sources (e.g., Lynch, 2001) suggests that most coaches employ psychological methods that are conventional to their respective sports and use techniques they have learned from other coaches. Typically these techniques include various forms of extrinsic motivation (e.g., pep talks, pregame speeches, etc.), positive verbal and nonverbal reinforcement (e.g., an encouraging word or a pat on the back), and punishment (e.g., extra physical conditioning or reduced playing time) (Smith, 2010). In contrast, the psychological assistance SPCs provide for athletes is based on their specialized training in sport psychology, including techniques for managing emotions under pressure, enhancing focus and composure, refocusing after a performance setback, maintaining confidence under adversity, and processing feedback from coaches (Weinberg \& Williams, 2010). ${ }^{10}$ 


\section{Why Should SPCs Be Given the Opportunity to Interact With NCAA D-1 Student-Athletes During Practices and Competitions?}

There appear to be at least three reasons why it would be beneficial to allow SPCs access to student-athletes and coaches during practices and competitions: To promote the development of mutual trust, to provide specialized psychological support, and to encourage the integration of mental skills with technical and tactical skills.

\section{To Promote the Development of Trust}

Perhaps the most important reason for permitting SPCs to interact with studentathletes and coaches during practices and competitions is to enhance the development of mutual trust between the parties (Petitpas, Giges, \& Danish, 1999). Athletes and coaches are more likely to trust the assistance of SPCs if they have had more frequent contact with them, particularly in situations that challenge the athletes' mental and emotional resources (e.g., during intense practices and heated competitions). According to one coach at a prominent D-I university, "gaining trust is the first step toward building respect" (Yukelson, 2010, p. 153). Current NCAA rules permit strength coaches to provide oversight of warm-up or physical conditioning activities before and during practices and before competitions without being considered 'countable' coaches (NCAA Educational Column-February 5, 2009) (NCAA LSDBi, 2010). Such interactions allow those support personnel to build trust and establish the credibility of their contributions to athletes' preparation for competition. Permitting SPCs similar opportunities would allow them to "develop rapport, listen attentively, speak the appropriate sport language, and earn the trust of both the coach and athlete and other personnel" (Yukelson, 2010, p. 160).

\section{To Provide Specialized Psychological Support}

As demands on NCAA D-I coaches have increased, roles that have been historically associated with coaches have been delegated to qualified support staff. In the not too distant past, coaches were responsible for warm up, flexibility, strength and conditioning and general medical treatment of student-athletes. However, with the increased pressure to win and other demands facing today's D-I coaches (e.g., identifying and signing the best recruits, fulfilling public relations responsibilities, fundraising, etc.) - as well as NCAA restrictions governing the amount of time coaches can spend in direct contact with athletes-they must concentrate their efforts on teaching the specific technical and tactical skills of their sport and must delegate other duties to support staff with specialized training. For example, certified athletic trainers and strength coaches provide nonsport specific assistance in preparing athletes for the physical demands of competition. In much the same way, if SPCs were allowed to interact with athletes during practices they could help athletes deal with the mental demands of their sport. For example, SPCs could reinforce the use of productive mental strategies for managing negative emotions when athletes become frustrated (e.g., from being replaced in a drill or pulled out of a game for making a mistake) or when they receive critical coach feedback. 


\section{To Encourage the Integration of Mental Skills with Technical and Tactical Skills}

Mental skills like technical and tactical skills improve with practice and, when rehearsed together, are more likely to become a more automatic part of athletes' performance in competition (Martens, 2004). Although research indicates that many elite Olympic athletes combine the practice of their mental, technical, and tactical skills on a systematic basis (e.g., Gould, Dieffenbach, \& Moffett, 2002; Greenleaf, Gould, \& Dieffenbach, 2001), such a custom does not appear to be commonplace at the collegiate D-1 level. ${ }^{11}$ For example, the results of one study of 670 collegiate athletes revealed an underutilization of the mental skill of goal setting (Burton, Weinberg, Yukelson, \& Weigand, 1998). It was recommended that the best way to address this deficiency would be to place increased emphasis on process-oriented performance goals during practices and competitions. If SPCs were permitted to interact with athletes during practices they could provide this type of specialized assistance as well as reinforce the use of other essential mental skills, such as arousal control (Williams, 2010), positive self talk, attentional focus (Vickers, 1997), and imagery (Vealey \& Greenleaf, 2010). A SPC might work with a basketball player to set and maintain a process goal of developing a preshot routine for her free throws that consists of a relaxation breath, a positive self statement (e.g., "nothing but net"), and a narrow visual focus on the target. Before each shot, the player could image herself being fouled in a tense game situation, going through her preshot routine, feeling confident, and making the free throw. By combining mental and physical rehearsal of the shot during practice the player would be more likely to reproduce the correct action in games (Post, Wrisberg, \& Mullins, 2010), regardless of the circumstances, and feel more confident in doing so (McKenzie \& Howe, 1997).

\section{Summary and Suggested Changes Regarding NCAA Rules Governing Sport Psychology Consultants}

In this paper we have provided a general overview of NCAA legislation and interpretations governing the activities of SPCs over the past two decades. We have also presented several examples of attempts made by professional organizations (AASP and APA) and NCAA D-I compliance officers to obtain clarification of the allowable activities of SPCs for the purpose of providing specialized psychological assistance for student-athletes. We have also suggested possible responses to the lingering questions concerning what SPCs do and don't do (specifically how the psychological assistance SPCs provide for athletes is different from that which coaches routinely offer) and how allowing SPCs to interact with student-athletes at practices and competitions would benefit both the athletes and coaches. We have argued that qualified SPCs are capable of providing specialized assistance commensurate with their training and experience and, therefore, should be permitted to deliver their expertise in a manner similar to that of other qualified noncoaching support staff (particularly certified athletic trainers and strength coaches). We now conclude the paper by suggesting at least two ways this objective could be accomplished. 
One solution would be to "fine tune" existing NCAA legislation. For example, Bylaw 11.7.1.1.1.1, Noncoaching Activities, as revised January 19, 2010 (NCAA LSDBi, 2010) could be amended to read as follows (changes noted in italics).

Institutional staff members involved in noncoaching activities (e.g., certified athletic trainers, strength and conditioning staff, sport psychology consultants, administrative assistants, academic counselors) do not count in the institution's coaching limitations, provided such individuals are not identified as coaches, do not engage in any on- or off- field coaching activities (e.g., attending meetings involving coaching activities, analyzing video involving the institution's or an opponent's team), and are not involved in any off- campus recruitment of prospective student-athletes or scouting of opponents.

This revision would not only add SPCs (along with certified athletic trainers and strength coaches) to the list of individuals currently involved in noncoaching activities but would also reinforce the notion that the services provided by SPCs represent another specialized form of support.

Another possible solution would be to clarify the roles and activities (and perhaps the necessary credentials) of all noncoaching staff by briefly characterizing what each does (italics added), rather than what they are prohibited from doing. A possible description of SPCs might read as follows:

\section{Sport Psychology Consultant}

A sport psychology consultant may provide assistance in the development of student-athletes' psychological skills (e.g., anxiety management, attention control, self-talk, arousal regulation, imagery, etc.) at both on- and off-field settings. A consultant must possess a graduate degree (master's or Ph.D.) with a specialization in sport psychology or must hold current Certified Consultant status with AASP. ${ }^{12}$ In some instances individuals in training (e.g., graduate students, interns) that are supervised or mentored by any of the above-mentioned persons may provide mental training services.

\section{A Final Comment}

While we acknowledge that there are a number of important factors mediating the employment of SPCs and the access they should be given to student-athletes-not the least of which are the approval and support of the coach and the athletic department's resources for providing appropriate funding for the services-we believe that it is essential for any SPCs retained by a NCAA D-I athletic department to be permitted to provide assistance in a way that is commensurate with their training and that affords the greatest benefit for student-athletes.

\section{Notes}

1. To our knowledge, the NCAA Manual contains no explicit definition of "coaching." A "Coach" is defined by NCAA Bylaw 11.01.2 Coach, Head or Assistant. A head or assistant coach 
is any coach who is designated by the institution's athletics department to perform coaching duties and who serves in that capacity on a volunteer or paid basis (NCAA, 2010).

2. The NCAA's organizational structure and legislative format were restructured in 1996 and those changes went into effect August 1, 1997. The references to "new structure" refer to these changes in the legislative procedure. Legislative recommendations, ideas or concepts may come from Conferences, the Management Council or Board of Directors directly, or be presented by a NCAA cabinet or committee. One of these groups must present the proposal to the Management Counsel for initial consideration (NCAA, 2010).

3. The assistance of Robert N. Singer, Past President, Division 47, American Psychological Association in compiling this proposal is gratefully acknowledged.

4. According to the New Oxford American Dictionary "coach" and "consultant" are distinguished as "an athletic instructor or trainer" and "a person who provides expert advice professionally," respectively (McKean, 2005).

5. While no formal documentation of this event has ever been obtained, the possibility that it took place is at least suggested in an NCAA Educational Column titled "Coaching Limitations - Use of Outside Consultants (Item Ref: Column 8 \#2) dated February 20, 1991. The statement reads as follows: "During its January 31, 1991, meeting, the NCAA Interpretations Committee reviewed the provisions of Bylaw 11.6.1.1.1 and determined that a member institution may not utilize a consultant from outside the institution (e.g., former professional athlete, skill instruction specialist) who is involved in any on-court or on-field activities on an individual or team basis without counting the consultant in the coaching limitations in that sport (italics added)" (NCAA LSDBi, 2010).

6. Although the NCAA Official Interpretation (Sports Psychologist Attending Practice Sessions, January 8,2003) permits SPCs to attend practices, confusion as to their allowable activities and acceptable interaction with student-athletes continues to linger, which in turn prevents them from assisting student-athletes in the most effective ways.

7. Paper distributed to SPCs attending a session on the topic of NCAA compliance issues held at the 2006 AASP conference, Miami, FL, September 29, containing the SPC's response to two NCAA staff interpretations (Sport Psychologist Attending Practice, January 8, 2003; Sports Psychologist/Use of Outside Consultants, July 2, 2003).

8. AAASP shortened the name of its organization to the Association for Applied Sport Psychology (AASP) in 2006. Source: Association for Applied Sport Psychology Newsletter, Fall/Winter 2006, Volume 21, Issue 3, p. 12.

9. As recently as October 19, 2010 the NCAA attempted to clarify the roles of coaching and noncoaching staff members in an educational column that states in part: NCAA Division I institutions should note that pursuant to NCAA Bylaw 11.7 any individual who participates in any manner in the coaching of a sport in practice, games or organized activities directly related to that sport must be counted as a coach as stipulated in the limitations for that sport. A strength and conditioning coach does not need to be included in the institution's coaching limitations for a specific sport provided the individual only conducts flexibility, warm up and physical conditioning activities before contests and before or during practices or other organized activities. In addition to maintaining competitive equity, the intent of the coaching limitations is to restrict the actual coaching of student-athletes to those individuals who are identified as coaches. . . Noncoaching staff members with sport-specific responsibilities (e.g., administrative assistants, directors of operations, quality control personnel, directors of player development, video coordinators, assistant/associate athletics directors for specific sports) do not have to be included in the institution's coaching limitations, provided they are not identified as coaches and do not engage in any coaching activities, on-court or on-field activities (e.g., shagging balls, assisting with drills, throwing batting practice, signaling in plays at the direction of a coaching staff member), offcampus recruiting activities or scouting opponents (NCAA LSDBi, 2010). 
10. While the present paper primarily emphasizes the benefits student-athletes might derive from having access to SPCs it could be argued that coaches might benefit from their assistance as well. In many respects coaches are performers too, meaning they, like their athletes, need to maintain focus and composure under pressure to do their jobs most effectively. In addition, coaches must be able to build team cohesion and maintain effective communication with their athletes as well as all the members of their staff. SPCs are a capable of providing assistance for coaches in meeting each of these challenges.

11. The authors know of no other examples in professional, Olympic, or other elite sport in which the activities of SPCs are restricted by governing body legislation.

12. For more detailed information about the criteria athletic departments should consider when hiring a qualified SPC we refer the reader to the AASP position paper "How to Choose a Sport Psychology Consultant" at www.appliedsportpsych.org/publications. Additional information regarding AASP certification may be found at www.appliedsportpsych.org.

\section{Acknowledgment}

Appreciation is extended to Dr. Joe Whitney, Director of Mental Training for the University of Tennessee Athletic Department for comments on an earlier draft of this paper.

\section{References}

Alvarez, B., \& Lucas, M. (2006). Don't flinch: Barry Alvarez: The autobiography. Champaign, IL: KCI Sports, LLC.

American Institutes for Research. (1988). Report No. 1: Summary results from the 19871988 national study of intercollegiate athletes. Studies of intercollegiate athletes. Palo Alto, CA: Center for the Study of Athletics.

Association for Applied Sport Psychology. (2011). About Certified Consultants. Retrieved from http://appliedsportpsych.org/consultants.

Burton, D., Weinberg, R., Yukelson, D., \& Weigand, D. (1998). The goal effectiveness paradox in sport: Examining the goal practices of collegiate athletes. The Sport Psychologist, 12, 404-418.

Gould, D., Dieffenbach, K., \& Moffett, A. (2002). Psychological characteristics and their development in Olympic champions. Journal of Applied Sport Psychology, 14, 172-204.

Greenleaf, C., Gould, D., \& Dieffenbach, K. (2001). Factors influencing Olympic performance: Interviews with Atlanta and Nagano U.S. Olympians. Journal of Applied Sport Psychology, 13, 154-184.

Kornspan, A.S., \& Duve, M.A. (2006). A niche and a need: A summary of the need for sport psychology consultants in collegiate sports. Annals of the American Psychotherapy Association, 19(7), 1-12.

Lynch, J. (2001). Creative coaching. Champaign, IL: Human Kinetics.

Mahoney, M.J. (1989). Sport psychology. In I. Cohen (Ed.), The G. Stanley Hall lecture series (Vol. 9, pp. 97-134). Washington, DC: American Psychological Association.

Martens, R. (2004). Successful coaching (3rd ed.). Champaign, IL: Human Kinetics.

McCann, S. (2004). Roles: The sport psychologist. In S. Murphy (Ed.), The sport psych handbook (pp. 279-291). Champaign, IL: Human Kinetics.

McKean, E. (Ed.). (2005). The New Oxford American Dictionary (2nd ed.). New York: Oxford University Press.

McKenzie, A., \& Howe, B.L. (1997). The effect of imagery on self-efficacy for a motor skill. International Journal of Sport Psychology, 28, 196-210.

NCAA Academic and Membership Affairs Staff. (2010). 2010-2011 NCAA Division I Manual. Indianapolis, IN: NCAA Academic and Membership Affairs Staff. 
NCAA Legislative Services Database-LSDBi [Computer Software]. (2010). Indianapolis, IN: The National Collegiate Athletic Association (NCAA).

Petitpas, A.J., Giges, B., \& Danish, S.J. (1999). The sport psychologist-athlete relationship: Implications for training. The Sport Psychologist, 13, 344-357.

Post, P.G., Wrisberg, C.A., \& Mullins, S. (2010). A field test of the influence of pre-game imagery on basketball free throw shooting. Journal of Imagery Research in Sport and Physical Activity, 5(1), Article 2. Retrieved from http://www.bepress.com/jirspa/ vol2015/iss2011/art2012.

Smith, R. (2010). A positive approach to coaching effectiveness and performance enhancement. In J.M. Williams (Ed.), Applied sport psychology: Personal growth to peak performance (6th ed., pp. 42-58). New York: McGraw-Hill.

Tod, D., \& Andersen, A. (2004). Success in sport psych: Effective sport psychologists. In S. Murphy (Ed.), The sport psych handbook (pp. 305-314). Champaign, IL: Human Kinetics.

Vealey, R.S., \& Greenleaf, C.A. (2010). Seeing is believing: Understanding and using imagery in sport. In J.M. Williams (Ed.), Applied sport psychology: Personal growth to peak performance (6th ed., pp. 267-304). New York: McGraw-Hill.

Vickers, J.M. (1997). Control of visual attention during the basketball free throw. American Journal of Sports Medicine, 24, 93-97.

Voight, M., \& Callaghan, J. (2001). The use of sport psychology services at NCAA Division I universities from 1998 - 1999. The Sport Psychologist, 15, 91-102.

Weinberg, R.S., \& Williams, J.M. (2010). Integrating and implementing a psychological skills training program. In J.M. Williams (Ed.), Applied sport psychology: Personal growth to peak performance (6th ed., pp. 361-391). New York: McGraw-Hill.

Williams, J.M. (2010). Relaxation and energizing techniques for regulation of arousal. In J.M. Williams (Ed.), Applied sport psychology: Personal growth to peak performance (6th ed., pp. 247-266). New York: McGraw-Hill.

Williams, J.M., \& Straub, W.F. (2010). Sport psychology: Past, present, future. In J.M. Williams (Ed.), Applied sport psychology: Personal growth to peak performance (6th ed., pp. 1-17). New York: McGraw-Hill.

Wilson, K.A., Gilbert, J.N., Gilbert, W.D., \& Sailor, S.R. (2009). College athletic directors' perceptions of sport psychology consulting. The Sport Psychologist, 23, 405-424.

Wrisberg, C.A., \& Johnson, M.S. (2002). Quality of life. In M. Kellmann (Ed.), Enhancing recovery: Preventing underperformance in athletes (pp. 253-267). Champaign, IL: Human Kinetics.

Wrisberg, C.A., Loberg, L.A., Simpson, D., Withycombe, J.L., \& Reed, A. (2010). An exploratory investigation of NCAA Division-I coaches' support of sport psychology consultants and willingness to seek mental training services. The Sport Psychologist, 24, 489-503.

Wrisberg, C.A., Simpson, D., Loberg, L.A., Withycombe, J.L., \& Reed, A. (2009). NCAA Division-I student-athletes' receptivity to mental skills training by sport psychology consultants. The Sport Psychologist, 23, 470-486.

Wrisberg, C.A., \& Whitney, B.J. (1999). Developing an applied sport psychology program at a Division I university. Paper presented at the meeting of the Third World Congress on Mental Training. Salt Lake City, UT.

Yukelson, D.P. (2010). Communicating effectively. In J.M. Williams (Ed.), Applied sport psychology: Personal growth to peak performance (6th ed., pp. 149-165). New York: McGraw-Hill. 